\title{
A Produção do Conhecimento Científico e Tecno- lógico no Âmbito dos Fundos Setoriais: o caso do Fundo Verde Amarelo
}

\author{
Marcos Dalsecco Braga Arcuri \\ Orientador: Fernanda Sobral \\ Dissertação de Mestrado \\ Data da defesa: 14.08.2012
}

E sta pesquisa trata do tema da produção do conhecimento científico e tecnológico no âmbito dos Fundos Setoriais de Ciência e Tecnologia (FS), política de financiamento a projetos de C\&T em áreas estratégicas para o desenvolvimento socioeconômico do país. Especificamente, foi realizada uma investigação sobre as formas de produção do conhecimento levadas a cabo nos projetos de um desses fundos, o Fundo Verde Amarelo (FVA), que tem como objetivo central promover a relação entre universidade e empresa, para a produção de inovação. Para definir conceitualmente as formas de produção do conhecimento, foram tomadas como referências as obras de autores centrais dos campos da Sociologia da Ciência e dos Estudos Sociais de Ciência e Tecnologia. De acordo com essas referências, observam-se mudanças nas formas de produção de ciência e tecnologia desde meados do século passado até os dias de hoje. Essas mudanças ocorrem mais claramente na participação de novos atores nesse processo e na aparição de novos lócus dessa produção.

A pesquisa sobre as formas de produção do conhecimento no FVA consistiu na análise de dados sobre os FS disponibilizados pelo MCTI e IPEA, na análise de questionários aplicados aos coordenadores de projetos do FVA, na análise de entrevistas realizadas com ex-membros do Comitê Gestor desse fundo e na análise das atas de reuniões desse comitê. A partir das informações coletadas, foi buscada a presença de características das novas formas de produção do conhecimento nos documentos oficiais que definem os objetivos e diretrizes do FVA, nas opiniões e posicionamentos dos membros do Comitê Gestor do fundo, nas informações sobre a elaboração e execução dos projetos do fundo cedidas pelos coordenadores e nos dados disponibilizados pelo MCTI e IPEA. Ao final das análises, observa-se que o governo brasileiro, na formulação dos FS, tomou como referência os modelos de produção de ciência, tecnologia e inovação predominantes nos países centrais do capitalismo, expoentes das novas formas de produção do conhecimento. Quanto aos projetos do FVA, concluiu-se que 
apesar de ter sido verificada a existência de algumas características das novas formas do conhecimento, não há uma prática consolidada das mesmas.

Palavras-chave: Ciência e Tecnologia, Produção do Conhecimento, Fundos Setoriais, Fundo Verde Amarelo. 